\title{
Interpreting the Functional Properties of Sportswear
}

\author{
Prof. Jonalee Bajpai, Phd., Govind Kapoor, Sanskriti Tulsyan \\ Department of Fashion Technology, National Institute of Fashion Technology, Bengaluru \\ DOI: 10.29322/IJSRP.11.06.2021.p11415 \\ http://dx.doi.org/10.29322/IJSRP.11.06.2021.p11415
}

\begin{abstract}
Functional clothing refers to a genre of clothing that is developed to meet very specific and niche requirements of the end user. It is a result of interference of multiple domains of product development, such as technical textiles and other construction technologies. There are four basic requirements of any functional clothing namely physiological, biochemical, ergonomic and psychological. This paper focuses on the requirement-based classification of sportswear properties and how they have been used to improve the performance of the sportsperson.
\end{abstract}

Index Terms- Functional Clothing, Requirements of Functional Clothing, Sportswear, Functional Properties

\section{INTRODUCTION}

$\mathrm{T}$ The term functional clothing is relatively new in the field of technical textiles and is primarily concerned with new product developments and technologies having niche applications. Recent and ever-growing advancements in technical fibers, fabrics, finishes, and garment manufacturing technologies have enabled the emergence of functional clothing. ${ }^{1}$

Functional clothing begins and ends with user-specific requirements and unlike fashion clothing not based on the designer's creative instincts. All the clothes serve the basic purpose of covering the body, protection from external elements like weather and aesthetics. Functional clothing has pre-defined purposes that perform more than basic requirements. Unlike the fashion clothing, functional clothing integrates with domain like medicine, physics, nanotechnology, biotechnology etc. These requirements are either defined by users or activities for which the apparel is designed. ${ }^{2}$ Sportswear is the category of clothing that is specifically made to be worn while being engaged in the designated sport to help the wearer improve their performance and ensure comfort as per the demands of the activity. This paper emphasizes on the characteristic properties of Sportswear that qualifies to categories sportswear as functional clothing and emphasizes on some of the trending sports apparel with functional properties.

\section{CLASSIFICATION OF FUNCTIONAL CLOTHING}

The standard classification of technical textiles is broadly done as Protech (protective textiles), Sportech (Sports textile), and Meditech (Medical textile). This classification covers only the material, i.e. textile, but not the end product unless the end product uses the textiles as it is (geotextiles). Innovation and product development from these materials into apparel opens a new arena of possibilities with the intervention of technologies from other domains. ${ }^{3}$

\section{REQUIREMENTS OF FUNCTIONAL CLOTHING}

Each class of functional clothing is designed for a well-defined purpose and functionality. However, in addition to specific functionality, all functional clothes must fulfill certain requirements which are common to all users. These considerations can be classified into following categories as in the flowchart below. Functional wear should be an effective integration of all these considerations into design and construction of clothing. 


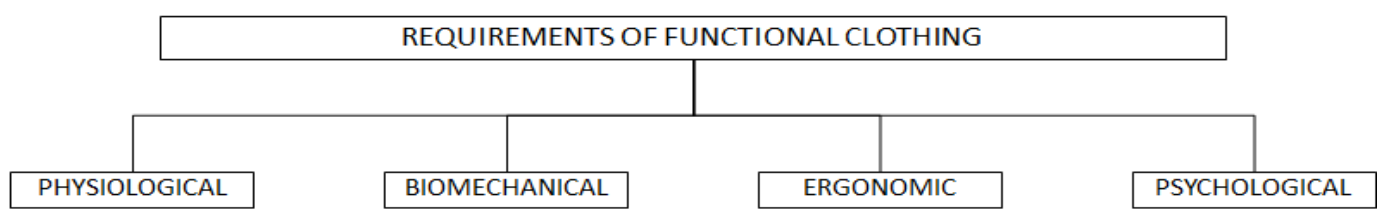

Figure 1: Requirements of functional clothing

\section{A. Sportswear and Physiological Functional Property}

These requirements refer to the physiology which means body functions and anatomy of the human body. This includes the size, shape, metabolism, mass and strength of a human body. Every functional cloth should give comfort to the human body and should not hinder natural body functions in any way. The extent of comfort depends on the size, mass, strength, shape, design and construction of the clothing. ${ }^{4}$ This property forms an integral part when it comes to sportswear. The fit and size of the garment decides the overall performance and appearance of the sportsperson. In case of functional clothing, garment dimensions are critical and is an important factor in determining safety and performance of the clothing. ${ }^{5}$

In light of the degree of athletic exercise and the user's physiology, the physical exertion level for each user is different. The physiological comfort will depend on Heat, liquid/ vapour transmission of clothing, and thermoregulatory response of the body along with skin sensory response and environmental conditions. ${ }^{6}$

Wear-comfort of a sportswear is one of the most important and crucial prerequisites. It is not just to keep the user comfortable; it also ensures better performance and efficiency. Sportspersons wear clothing to keep themselves cool and dry which is a physiological requirement. Not following such functional clothing will lead the body temperature to rise rapidly causing discomfort, resulting in a reduced efficiency and performance. ${ }^{7}$

A great number of technical textile types and brands for personal thermal management have been exploited, such as Omni-heat (Columbia), CoolMax (Dupont), AeroReact (Nike), Dri-FIT (Nike), Verycool (Yonex), HeatGear (Under Armour), ForMotion (Adidas), Gore-Tex, etc. They are intended to offer improved thermal comfort for the human body by means of different courses for grouped situations, for example, material innovation, fiber engineering, finishes, new structure design,and garment shape improvement. ${ }^{8}$ Nike presented a smart shirt called "sphere react shirt" containing vents with about 10 mm diameter that open up when the wearer sweats to permit heat and moisture escape and automatically closes in dry state. ${ }^{9}$

\section{B. Sportswear and Biomechanical Functional Property}

Biomechanics can be defined as the study of mechanical aspects of the human body. Biodynamic studies biological motions with special reference to the mass and forces involved. ${ }^{10}$ Biomechanics include kinematic, dynamic and behavioral analysis of human activity. In fact biomechanics is the science of movement techniques which finds direct application to sports where technique is most dominant than physical or even physiological factors. Thus, the principles of Biomechanics are used in sportswear as a performance enhancer or reduction of risk of injury. ${ }^{11}$ With substantial understanding of sports dynamics and biomechanics, brands and designers are pushing the boundaries of sportswear and producing some extraordinary functional clothing for different sport types.

All sport activities have a different involvement of muscles. It is important to understand the biomechanical requirement of the sport before designing the specialized garment. Compression garments, which are the most common and direct application of the biomechanical factor, have to be made in a manner to suit the activity and enhance performance delivery of the user. ${ }^{12}$ A suitable example for this would be the "LZR swimsuit" by Speedo that reduces the drag by $38 \%$ and results in an increased speed $4 \%$ of the swimmers. It was the suit that is believed to be the reason for the multiple records set in the Beijing Olympics. The fabric used consists of small microfibers of nylon and spandex in a highly dense weave. The suit fits the swimmers' body snugly and the compressions created on muscles prevent muscle vibrations (that increase drag) all without hindering the body movement. ${ }^{13}$ Yet another fitting example could be from the Australian sportswear company named 776BC's that measures biomechanics in motion. These garments are extremely successful for getting exact ongoing readings as they utilize a lot of visual anatomical markers which are intended to focus attention on specific body points and key lines. The data obtained from the wearers' actions allows the athlete to harness real-time biomechanical feedback which can be used to achieve best practice form and function in an exercise or activity. ${ }^{14}$

This publication is licensed under Creative Commons Attribution CC BY. 


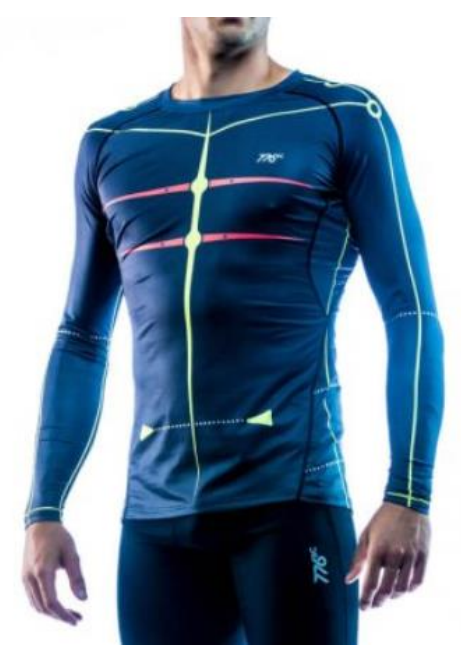

Figure 2 Men's Motion Pro Series Base Layer - Black by 776BC

\section{Sportswear and Ergonomic Functional Property}

Ergonomics is the science of work: of the people who do it and the ways it is done; the tools and equipment they use, the places they work in, and the psychosocial aspects of the working situation. ${ }^{15}$ It about modifying the work or the workplace or the work equipment to fit the user. The purpose is to reduce risk of short term or long term injury.

Functional clothing in general and sportswear in particular should also meet its relevant functional requirements in terms of ergonomics. Studies show protective clothing when poorly designed or of poor fit can cause limitations in physical activities and can hinder the workspace environment. This can increase the risk of failure of functional clothing. ${ }^{16}$

Research say that compared to a semi-nude body, the movement, speed, accuracy and range of motion may be reduced in a clothed body, while muscular exertion may be increased. The integral joint mobility of an astronaut can be reduced by $20 \%$ in typical spacesuit. ${ }^{17}$

Sportswear designing have to integrate factors such as the sport type, activity level and the duration of the sport. All these factors affect the ergonomic aspect of a sportswear - it is due to this reason that every sport has its own different specialized apparel that ensure optimum efficiency and comfort of the sportsperson. ${ }^{18}$

A suited reference of the influence of ergonomics on sportswear is the advent of sports bras for female athletes. The sports bras enhanced reduced movement of the breast and pain during locomotion by using molded cups and compression designs to flatten the breast. ${ }^{19}$

An otherwise very simple product like socks can be the reason for increased mobility by combating fatigue. Crane ergonomic cycling socks are ergonomically shaped and have reinforced ankle and instep protection. The socks have heel and toe cushioning, arch support and Achilles tendon pad. It has Triaxis bandage to support and stabilize the ankle with compression to combat fatigue and integrated padding systems in areas where extra support is needed. ${ }^{20}$

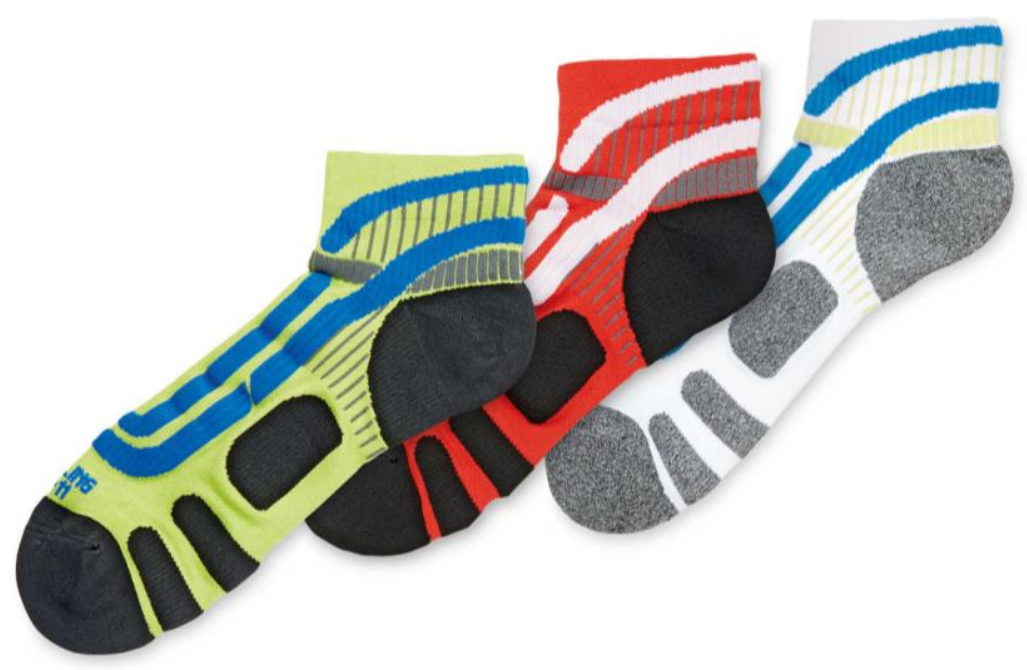

Figure 3 Crane ergonomic cycling socks 


\section{Sportswear and Psychological Functional Property}

Garments are an essential part of our day to day lives and signifies self-worth and belongingness. Psychological aspect relates to how a garment is perceived by human minds. ${ }^{21}$

Functional and aesthetic property are the two sides of the coin. Along with all the mentioned functional properties, aesthetic plays an important role in sportswear as well. The product should look smart, stylish and aesthetically appealing. It should impart psychological as well as physical boost. Psychological aspects should be considered while designing the product so as to create a fully functional garment which is in tune with the social and cultural background of the user. ${ }^{22}$

It is important to fulfill the psychological requirements for a person to do justice to the apparel that has been designed to improve their performance. Multiple studies suggest the importance of subjective norms has direct, significant relationships with attitude, perceived behavioral control, and purchase intention. ${ }^{23} \mathrm{~A}$ lot of companies have also realized the importance of incorporating such factors that influence the sports person directly to boost their confidence and performance.

Apart from aesthetics, colour plays a huge role in the performance of a sport-person psychologically. A research conducted in 2004 Olympics showed that in sports such as boxing, wrestling and taekwondo, the player wearing red body protection had a higher chance of winning. The reason is simply stated as the fact that across the animal kingdom the colour red is marked as the colour of dominance, and aggression. ${ }^{24}$

When Nike developed Pro TurboSpeed suit for London Olympics 2012 which enabled athletes to move faster through air than bare skin, they sought insight from athletes as to what gives them a mental boost. Based on that the product was developed with fluorescent yellow strips on the inside arm and the legs as contrast patches made the athletes feel faster. ${ }^{25}$

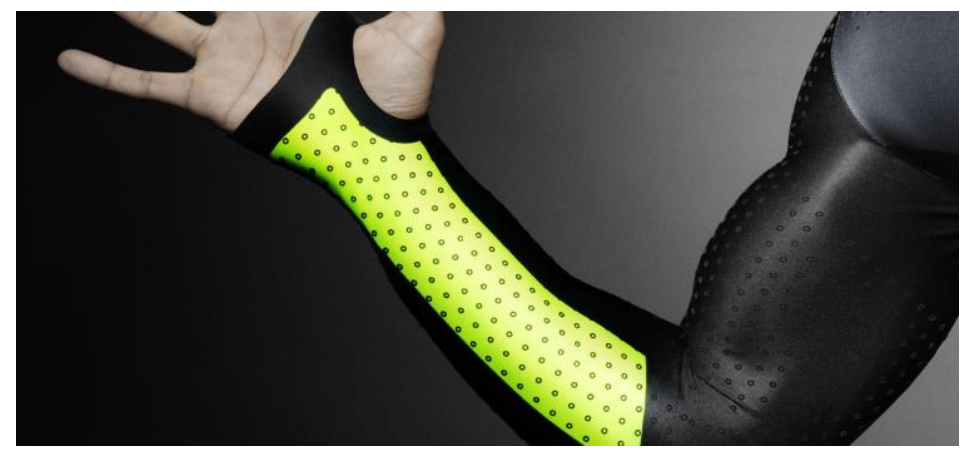

Figure 4 Nike Pro Turbo Speed suit

\section{CONCLUSION}

Functional clothing is not only limited to Industrial, astronomical or activities that exposes oneself to extreme weather conditions. With the advent of rigorous research and development by brands, sportswear qualifies to be categorized as Functional clothing. Sportswear integrates all the properties of functional clothing like the Physiological, Biomechanical, Ergonomics and Psychological properties. Physiological, Biomechanical and Ergonomic properties form an integral part of sportswear, that enhances the overall performance and efficiency of the wearer by imparting physical comfort, reducing physical exertions, enhancing speed and mobility and above all reduction of risk due to injury. Psychological properties in sportswear like colour, design elements, prints have profound effect on the mind of the sportsman that can impart physical as well as mental boost.

\section{REFERENCES}

[1] Gupta, D., 2011. Functional clothing-Definition and classification.

[2] Gupta, D., 2011. Design and engineering of functional clothing.

[3] Gupta, D., 2011. Functional clothing-Definition and classification.

[4] Gupta, D., 2011. Design and engineering of functional clothing

[5] Gupta, D., 2014. Anthropometry and the design and production of apparel: an overview. In Anthropometry, Apparel Sizing and Design (pp. 34-66). Woodhead Publishing.

[6] Ziemele, I., Šroma, I. and Kakarāne, A., 2018. Comfort in Sportswear. In Key Engineering Materials (Vol. 762, pp. 402-407). Trans Tech Publications.

[7] Bartels, V.T., 2005. Physiological comfort of sportswear. In Textiles in sport (pp. 177-203). Woodhead Publishing.

[8] Peng, Y. and Cui, Y., 2020. Advanced Textiles for Personal Thermal Management and Energy. Joule.

[9] Rossi, R.M., 2018. High-performance sportswear. In High-Performance Apparel (pp. 341-356). Woodhead Publishing.

[10] Hatze, Herbert (1974). "The meaning of the term biomechanics". Journal of Biomechanics. 7 (12): 189-190.

This publication is licensed under Creative Commons Attribution CC BY 
[11] Retrieved from https://www.physio-pedia.com/Biomechanics_In_Sport

[12] Luo, J., Mao, A., Au, J.S., Li, Y. and Zhang, X., 2014. Fusion of art and technology in professional cycling sportswear design. Leonardo, 47(2), pp.176-178.

[13] http://sitn.hms.harvard.edu/flash/2008/issue47-2/

[14] https://www.mirrorreview.com/776bc-modernizing-sports-biomechanics-with-motion-and-true-athlete-insights/

[15] Pheasant, S. and Haslegrave, C.M., 2005. Bodyspace: Anthropometry, ergonomics and the design of work. CRC press.

[16] Bartkowiak, G. and Greszta, A., 2019. Determination of a Comfort Class for Protective Clothing Based on Ergonomic Tests. Fibres \& Textiles in Eastern Europe, 27(5), pp.65-74.

[17] Duffy, V.G., 2007. Digital human modeling. Springer-Verlag Berlin Heidelberg.

[18] Kanat, Z.E., 2018. Sportswear. In Waterproof and Water Repellent Textiles and Clothing (pp. 367-390). Woodhead Publishing.

[19] https://us.humankinetics.com/blogs/excerpt/ergonomic-considerations-for-sports-clothing

[20] https://www.aldi.co.uk/crane-ergonomic-cycling-socks-pair/p/074700129419100

[21] Kidd, L.K., 2006. A case study: Creating special occasion garments for young women with special needs. Clothing and Textiles Research Journal, $24(2)$, pp.161-172.

[22] Gupta, D., 2011. Design and engineering of functional clothing.

[23] Nam, C., Dong, H. \& Lee, Y. Factors influencing consumers' purchase intention of green sportswear. Fash Text 4, 2 (2017). https://doi.org/10.1186/s40691-017-0091$\underline{3}$

[24] https://www.bbc.com/future/article/20120731-wear-red-to-win-gold

[25] https://www.scmp.com/lifestyle/health-beauty/article/1855973/performance-sportswear-gives-psychological-well-physical

\section{AUTHORS}

First Author - Prof. Jonalee Bajpai, PhD., National Institute of Fashion Technology, Bengaluru, jonalee.bajpai@nift.ac.in. Second Author - Govind Kapoor, B.F.Tech (2016-20), National Institute of Fashion Technology, Bengaluru, govinddotkapoor@gmail.com.

Third Author - Sanskriti Tulsyan, B.F.Tech (2016-20), National Institute of Fashion Technology, Bengaluru, Sanskriti.tulsyan@gmail.com. 